\title{
Scleral Patch Graft With Fibrin Adhesive For Post Pterygium Scleral Thinning
}

\author{
Dr.Shivananda $\mathrm{N}^{\star, 1}$, Dr. Neeta Pal ${ }^{\dagger \dagger, 2}$, Dr. Frederick Korir ${ }^{\S, 3}$ \\ ${ }^{1}$ Aravind Eye Hospital, Pondicherry \\ ${ }^{2}$ Aravind Eye Hospital, Pondicherry. Current Affiliation: Disha Eye Hospital, Kolkata \\ ${ }^{3}$ Aravind Eye Hospital Current affiliation: Lighthouse for Christ Eye Center, Mombasa, Kenya \\ DOI: https://doi.org/10.15520/jcmro.v2i02.128
}

Accepted 11-02-2019; Received 7-02-2019; Publish Online 13-02-2019

\section{Reviewed By: \\ RICHARD GEORGE \\ Department: \\ Reviewer/CMRO}

\begin{abstract}
Scleral patch graft is commonly done for scleral thinning post pterygium surgeries. This procedure is done with sutures. Review of literature revealed few such cases. Scleral patch graft with fibrin glue has not been done so far. The novelty of our procedure is that we have applied fibrin glue to the scleral bed and pasted the graft over it. Then this graft was secured with minimal sutures. This not only saves the operative time but also increases patient comfort post op. Herein, we present a case of post pterygium surgery scleral melt successfully treated with scleral patch graft with fibrin adhesive
\end{abstract}

Key words: Pterygium-Scleral Patch Graft-Fibrin adhesive

\section{INTRODUCTION:}

The human sclera is a roughly spherical, relatively avascular, white, rigid, dense connective tissue that covers the globe posterior to the cornea [1] . It is opaque and appears white due to the high water content and haphazardly arranged collagen fibers. This provides strength and rigidity to the globe despite its constant movement and the pull exerted by the extraocular muscles [2] .

On average, the sclera is thickest posteriorly near the optic nerve (1.0-1.35 mm), decreasing gradually as it approaches the equator of the globe $(0.4-0.6 \mathrm{~mm})$ and it is about $0.8 \mathrm{~mm}$ at corneoscleral limbus [3] . Scleral thinning can occur in various conditions, including myopic degeneration, chronic scleritis, local scleral pathologies and scleral injury. Scleral thinning can result after excessive use of cautery in the scleral bed or overuse of antimetabolites. Prolonged irradiation, transscleral diode laser cycloablation, strabismus surgery and deep sclerectomy procedures can also predispose the sclera to thinning. Autoimmune conditions or collagen vascular diseases are known to present with scleral pathologies, which can also lead to scleral thinning [4]

\footnotetext{
* Email: drshivan@rediffmail.com

$\dagger$ Corresponding author.

¥ Email: neeta.pal1809@gmail.com

§ Email: f_kipkoech@hotmail.com
}

\section{CASE REPORT:}

A 40yrs old lady came with complaints of occasional pain and irritation in her LE over past 7 yrs. She had history of pterygium excision in the same eye 7 yrs back. She had been using topical and systemic medications on and off over past 7 yrs for pain relief.Her best corrected visual acuity in both eyes was $20 / 20$. Her IOP in RE was $16 \mathrm{mmHg}$ and LE was $15 \mathrm{~mm} \mathrm{Hg}$. On examination, RE showed grade 1 nasal pterygium and LE showed severe scleral thinning measuring (3x3) $\mathrm{mm}$ in size and approximately $90 \%$ of the depth of sclera at the site of previous pterygium excision(Figure 1).

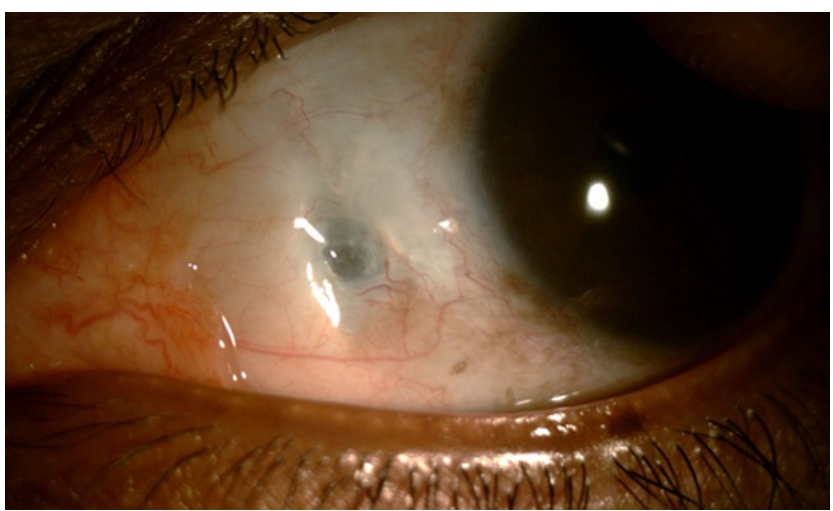

Figure 1. Post pterygium scleral melt: Note theextreme thinning of the site of previous pterygium excision 
Her hematological examinations showed hemoglobin $11.6 \mathrm{gm} / \mathrm{dl}$, WBC count 7300 cells/microliter, RBC count 4 million cells/microliter, bleeding time $1 \mathrm{~min} 45$ seconds and clotting time $5 \mathrm{~min}$. Her fasting blood sugar was $85 \mathrm{mg} / \mathrm{dl}$. There were neither any systemic conditions like collagen vascular disorders nor any history of trauma. There were no records of the previous surgery with the patient. Thus she was diagnosed to have primary pterygium in RE and post pterygium surgery scleral melt in the LE.

\section{SURGICAL TECHNIQUE:}

She was advised scleral lamellar patch graft for LE. Donor sclera was harvested from previously enucleated eye ball kept soaked in glycerol media. She was given peribulbar anesthesia. After sterile cleaning and draping, the area of scleral thinning was well-defined and exposed. The area of thinning was measured with caliper and $(3.5 \times 3.5) \mathrm{mm}$ size of lamellar scleral graft was dissected from the donor. After drying the scleral bed a thin layer of fibrin glue was applied over it. Then donor tissue was placed over this fibrin layer and waited for two minutes till the graft gets pasted over the scleral bed. Then this graft was anchored with three 10-0 nylon monofilament sutures. The donor size should preferably be larger than the thinned scleral bed. The scleral graft was then covered with conjunctival limbal autograft from the same eye temporal side. This autograft was secured to the scleral graft with fibrin glue. Postoperatively, she was treated with gatifloxacin- dexamethasone eye drops starting 4times daily and tapering weekly over one month, hydroxypropyl methyl cellulose eye drops 4 times daily and systemic anti-inflammatory medications. Postop day 1, both the scleral and conjunctival grafts showed good apposition. She was discharged and asked to review after 2 weeks. Her postoperative recovery was uneventful. On subsequent follow ups, her eye was quiet with both scleral and conjunctival autografts showing good apposition. She was continued the same postop regimen for rest of the month and then medications were discontinued. She was then asked to come for monthly follow up. At 3 months postop, she was symptomatically fine with well apposed conjunctival and scleral grafts(Figure 2).

Thus we conclude that scleral patch graft using fibrin glue is a successful modality of treatment for scleral thinning post pterygium surgery.

\section{DISCUSSION:}

Scleral thinning post pterygium surgery could be due to systemic predisposition or local risk factors like loss of conjunctival autograft with tssue glue, overenthusiastic use of antimetabolites, excessive intraoperative cautery or irradiation [5] . Our patient did not have any systemic disorders but local risk factors could not be ruled out due to lack of previous surgery details.

Scleral lamellar patch grafting primarily with fibrin glue is not done commonly. There is no data available in litera-

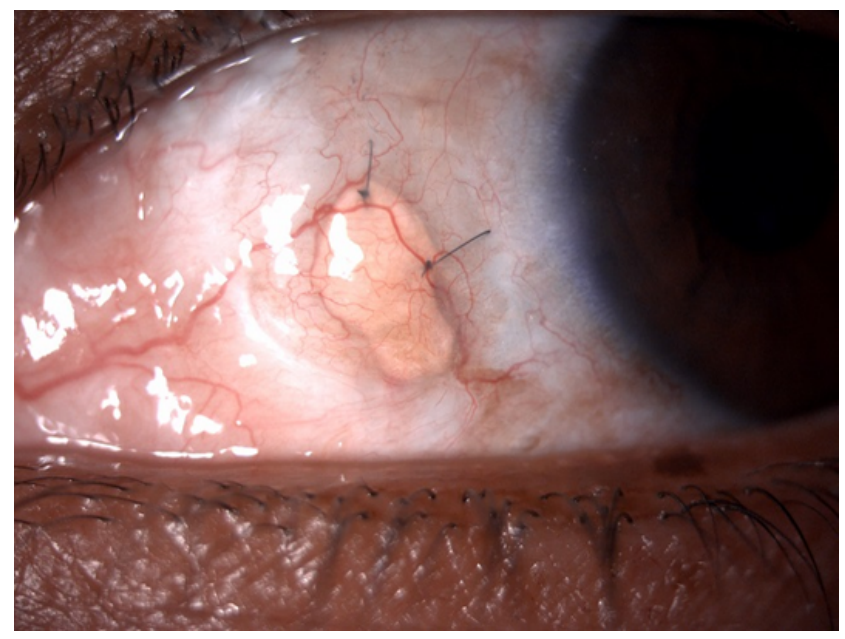

Figure 2. Scleral patch graft with fibrin: 3monthsfollow-up showing good graft apposition

ture regarding scleral patch graft with fibrin glue for management of post pterygium scleral thinning. Its add on advantages are early postop healing, more patient comfort and better cosmetic appearance. Scleral grafting with overlying conjunctival or amniotic membrane graft is an effective and simple measure for preserving globe integrity both structurally and functionally [5]. Surgical reinforcement of the pathologically thinned sclera improves the tectonic stability of the globe and helps prevent globe rupture [3] [4] .

Nevertheless, prompt diagnosis, systemic immunosuppressant use and early surgical closure with a scleral patch graft might prevent further complications. Multilayered amniotic membrane grafting is one alternative in scleral thinning. This helps epithelialization and healing. Fibrin glue can be applied in the defined scleral bed in selected cases of impending perforation [2] . Fibrin adhesive is a two-part material consisting of one part fibrinogen and one part thrombin. When the two components of a fibrin adhesive combine, they quickly polymerize to form a complex that is both chemically and ultrastructurally identical to a human plasma clot [6] . Scleral patch graft is the best choice in severe thinning. Regular follow-up with postoperative antiinflammatory medications is mandatory in these patients.

\section{REFERENCES}

[1] Dawson DG, L J. Edelhauser HF, editor. Ubels;. Adler's physiology,page 115,119.

[2] Agarwal A. Dhivya Ashok Kumar,Scleral thinning a complication after pterygium excision. Ocular Surgery News U.S. Edition; 2010.

[3] Stunf S, Lumi X. Preserved scleral patch graft for unexpected extreme scleral thinning found at the scleral buckling procedure: A case report,Indian. J Ophthalmol. 2011;59(3):235238.

[4] Nguyen QD, Foster CS. Scleral patch graft in the management of necrotizing scleritis; 1999.

[5] VS1 S, V J. Gupta P,Structural and functional outcome of scleralpatchgraft, Eye (Lond). 2007 Jul;21(7):930-5. Epub; 2006. 
[6] Hovanesian JA. Three newer methods for treating pterygium, published dec22; 2009. 